\title{
4
}

\section{SERVIÇO SOCIAL E LUTAS SOCIAIS: DESAFIOS PROFISSIONAIS EM TEMPOS DE BARBÁRIE}

Social work and social struggles: challenges for the profession in times of barbarism

\author{
Maria Beatriz Costa Abramides* \\ https://orcid.org/0000-0001-6347-8624
}

\begin{abstract}
RESUMO
O artigo Serviço Social e Lutas Sociais: Desafios para a profissão em tempos de barbárie tem como referência o momento contemporâneo do capitalismo, que se expressa em sua crise estrutural sistêmica, a partir de meados dos anos 70 donde estabelece ataques consecutivos sobre a classe com um conjunto de contrarreformas na esfera do estado e do mundo do trabalho, ampliando a superexploração e retirando direitos sociais e trabalhistas. A atenção se volta para o desmonte da nação em nosso país, desde o final dos anos 80, e com maior velocidade a partir do golpe de direita em 2016 com o governo de Temer, e de forma brutal a partir de 2019 com o desgoverno neofascista de Bolsonaro, de extrema direita. Neste diapasão, a partir de 2019 na China e 2020 no Brasil, inicia-se uma crise sanitária com a pandemia da COVID-19. No interior da luta de classes, expressamos a resistência e o fio condutor da formação e do trabalho profissional articulado às lutas sociais e compromisso histórico com os trabalhadores e como trabalhadores. Essa ambiência sócio-histórica nos traz desafios constantes que estão sendo enfrentados para se contrapor a barbárie do capital em sua expressão neofascista no país na perspectiva da lutas imediatas e históricas na direção da sociabilidade emancipatória.
\end{abstract}

\section{PALAVRAS-CHAVE}

Lutas Sociais. Serviço Social. Crise do capital. Emancipação humana.

\section{ABSTRACT}

The article Social Work and Social Struggles: Challenges for the profession in times of barbarism has as reference the contemporary moment of capitalism, which is expressed in its systemic structural crisis, starting in the mid-70s, where it establishes consecutive attacks on the class with a set of counter-reforms in the sphere of the state and the world of work, expanding overexploitation and removing social and labor rights. Attention has been focused on the dismantling of the nation in our country since the late $1980 \mathrm{~s}$, and with greater speed since the right-wing coup in 2016 with the Temer government, and brutally from 2019 with the neofascist mismanagement Bolsonaro, far right. In this tuning fork, starting in 2019 in China and 2020 in Brazil, a health crisis begins with the pandemic of COVID-19. Within the class struggle, we express the resistance and the guiding thread of training and professional work linked to social struggles and historical commitment to workers and as workers. This socio-historical ambience brings us constant challenges that are being faced to

\footnotetext{
* Assistente social. Doutora em Serviço Social. Docente do Departamento de Fundamentos do Serviço Social. Pontifícia Universidade Católica de São Paulo. (PUCSP, São Paulo, Brasil). R. Monte Alegre, no. 984, Perdizes, São Paulo (SP), CEP.: 05014-901. E-mail: biabramides@gmail.com.
}

DOI 10.22422/temporalis.2021V21n41p19-33

(cc) Br

Autora(s)/O(s) Autor(es). 2019 Acesso Aberto Esta obra está licenciada sob os termos da Licença Creative material em qualquer suporte ou formato, bem como adaptar, transformar e criar a partir deste material para qualquer fim, mesmo que comercial. O licenciante não pode revogar estes direitos desde que você respeite os termos da licença.

Temporalis, Brasília (DF), ano 21, n. 41, p. 19-33, jan./jun. 2021. | ISSN 2238-1856 
counter the barbarism of capital in its neo-fascist expression in the country in the perspective of immediate and historical struggles towards emancipatory sociability.

\section{KEYWORDS}

Social struggles. Social work. Capital crisis. Human emancipation.

\section{INTRODUÇÃO}

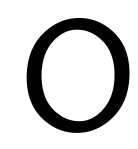

presente artigo trata dos desafios profissionais, em sua relação com as lutas sociais, em tempos de barbárie imposta pelo capital, sob o solo histórico de sua crise estrutural no plano internacional e com as programáticas adotadas nos países periféricos, como os da América Latina, na particularidade do Brasil, especialmente em meio a uma crise sanitária no planeta, a partir de 2020.

O debate para a profissão está ancorado no Projeto Ético-Político Profissional do Serviço Social Brasileiro (PEPP)'. Em todo este percurso, desde o Congresso da Virada, ao longo dos últimos 42 anos, lutamos contra a ditadura civil-militar-empresarial, pela democratização do país, e partir dos anos 90, contra os ataques do capital aos trabalhadores, que traz como consequência a sucessiva destruição de direitos sociais e trabalhistas. Com maior celeridade isto se ampliará, enormemente, a partir do governo golpista de Temer, de 2016 a 2018, e de forma demolidora a partir de 2019 no desgoverno do capitão reformado neofascista de Bolsonaro. Uma vez mais, continuamos na luta por meio de nossas organizações combativas da formação e exercício profissional, respectivamente ABEPSS e Conjunto CFESS-CRESS, assim como pela representação estudantil, ENESSO em articulação com os movimentos sociais classistas.

A crise sanitária mundial se desencadeia no Brasil a partir de março de 2020, sob um desgoverno negacionista. Um ano após o início da pandemia da COVID-19, em março de 2021, o Brasil apresenta o maior número de mortes diárias, de todos os continentes. É neste contexto que nos dirigimos à formação e ao exercício profissional, buscando socializar as informações com debates articulados às exigências da práxis cotidiana reafirmando as diretrizes curriculares e nosso Código de Ética, no horizonte de uma sociabilidade emancipada, livre e igualitária para todos os indivíduos sociais.

\section{CRISE ESTRUTURAL DO CAPITAL}

No artigo me detenho ao momento contemporâneo do capitalismo internacional exportação de capitais, financeirização da economia, capital portador de juros e que adquire a forma de mercadoria consubstanciada em empréstimos a serviço do imperialismo, o estágio superior do capitalismo (LÊNIN, 2012). São tempos de crise

\footnotetext{
${ }^{1}$ Cabe lembrar que o PEPP, como carinhosamente o denominamos, é herdeiro da direção social da profissão deliberada no III CBAS, em 1979, no famoso e emblemático Congresso da Virada, posto que, de forma pública e coletiva, a categoria rompe com o conservadorismo na profissão, conquista sua hegemonia em um processo permanente de ruptura, o que pressupõe uma categoria profissional fortemente organizada. Naquele momento as(os) assistente sociais se reconhecem como trabalhadoras(es), inscritos na divisão sócio-técnica do trabalho mais recentemente, corretamente assumida, como divisão sócio-técnica-racial e sexual do trabalho, em nossa condição de trabalhadoras(es) assalariadas(os); no compromisso profissional com a classe trabalhadora na defesa dos direitos sociais e trabalhistas conquistados nas lutas sociais.
} 


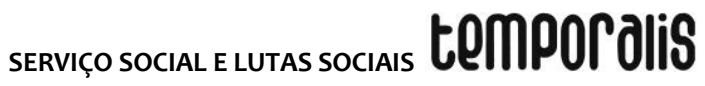

civilizatória que materializam a barbárie. Cabe-nos sinalizar os desafios postos ao conjunto da classe trabalhadora, e em seu interior às (aos) assistentes sociais, pesquisadoras(es), docentes, estudantes de Serviço Social, no sentido de fazer frente à destruição da sociabilidade humana e da natureza.

Vivencia-se uma quadra histórica de avanço do neoconservadorismo, do reacionarismo de direita e extrema-direita, da apologia do fim da história, de negação das classes sociais e da categoria trabalho; de hegemonia do capitalismo e do capital no plano internacional, apesar de sua fase de decomposição; da política de conciliação de classes, desenvolvida por projetos democrático-populares que cooptaram setores classistas do movimento sindical e popular, consequentemente de suas lutas, deixando-os atados à imediaticidade, com uma perspectiva reformista, politicista, distante do processo das grandes mobilizações, greves e outras ações diretas realizadas nos anos 80 . Este tempo requer a retomada de lutas sociais classistas, autônomas no campo de esquerda com unidade na luta, na perspectiva antifascista, anti-imperialista, anticapitalista, em direção à conquista do socialismo; perspectiva presente em nosso PEPP na articulação com o projeto societário igualitário e libertário, socialmente referenciado.

O capitalismo, por meio das leis gerais de acumulação, apresenta crises cíclicas periódicas. Em seu estágio atual emerge na esfera internacional, uma crise estrutural, metabólica e sistêmica desencadeada a partir de meados dos anos 70, resultante da progressiva queda das taxas de lucro; do fenômeno da estagflação, que corresponde à estagnação econômica, com altos índices de inflação; da crise de superprodução e crise do petróleo como seus vetores. O conjunto dessas determinações impõe novas estratégias de recomposição orgânica do capital que sob orientação macroeconômica de financeirização da economia, viabiliza a centralização do grande capital dos oligopólios e das corporações internacionais, sob o jugo das superpotências imperialistas no âmbito de sua internacionalização.

A questão da classe social é essencial em nossas análises históricas e teóricas, posto que a sociedade de classes apresenta-se em seu antagonismo, na apropriação privada dos meios de produção pelos capitalistas e na produção do trabalho socialmente combinado pela classe trabalhadora; tendo o protagonismo e a centralidade do proletariado, no processo da luta de classes, por produzir valor e mais valor para o capital, por seu trabalho alienado, fetichizado, explorado e reificado. A luta do proletariado deve se orientar na direção de um processo de superação da ordem burguesa, juntamente com o conjunto da classe trabalhadora, explorada e oprimida pelo capital que luta incessantemente, com todas as suas forças, para garantir seu poder econômico, social, ideológico na manutenção da desigualdade de classes, inerente à ordem burguesa de exploração, dominação, e controle da classe trabalhadora.

Os movimentos sociais e populares tem um papel decisivo na luta de classes e na formação da consciência de classe, que se desenvolve a partir da práxis política, da ação de massas, da organização e formação política, do trabalho de base; da mobilização e organização classista a partir de suas lutas imediatas e históricas, das ações diretas pelas mobilizações de ruas, ocupações de terra no campo e na cidade; ocupações de fábricas autogeridas; greves parciais e gerais; ou seja, é a luta concreta , cotidiana, coletiva das massas trabalhadoras, nos movimentos sociais, sindicais, populares que pode impulsionar 0

Temporalis, Brasília (DF), ano 21, n. 41, p. 19-33, jan./jun. 2021. | ISSN 2238-1856 
avanço da consciência de classe. Ressalto a importância de uma frente única classista, de lutas para fazer frente ao capital, ao Estado à seu serviço e ao governo fascista a ser construída, notadamente em uma conjuntura avassaladora contra as massas trabalhadoras, e de forma mais violenta em um desgoverno de extrema-direita como o que está e curso no Brasil desde 2019. Cabe explicitar a necessidade de construção de programas e partidos revolucionários para o processo histórico de superação do capitalismo expresso na face contemporânea da barbárie. As ações espontâneas, dispersas não podem levar a um processo de ruptura com a ordem capitalista e construção de uma sociedade sem classes, sem propriedade privada dos meios de produção, pelo fim do trabalho explorado, alienado, pelo fim do Estado de dominação, pela auto-organização dos indivíduos livremente associados, a sociedade comum a todos, a sociedade comunista como nos explicitavam Marx e Engels.

A decomposição do capitalismo em crise não pressupõe que haja uma crise terminal, embora se perfile em uma crise global, recompondo-se às custas das guerras, do avanço bélico, para recuperar seu poder de acumulação. Ocorre ainda a retração, cada vez maior, dos gastos com políticas sociais; o fundo público é deslocado para favorecer as grandes empresas, os oligopólios, o sistema bancário o que ocasiona a situação violenta impostas às massas trabalhadoras, destituídas de seus direitos que são cada vez mais vilipendiados. Os trabalhadores explorados e oprimidos, maioria da população, compõem o seguimento majoritário de nosso trabalho profissional posto que as expressões da questão social, suas inflexões e novas configurações se constituem em desafio permanente ao nosso projeto de profissão.

No mundo do trabalho, na esfera da produção social, a estratégia é a da acumulação flexível com desemprego estrutural, desregulamentação das relações de trabalho: trabalho intermitente, temporário, informal, precarizado, por pessoa jurídica, por tempo determinado, por projeto, sem carteira assinada, terceirização para atividades meio e fins, em que se amplia a superpopulação relativa desde a assim chamada acumulação primitiva (MARX, 2017b). As múltiplas formas de existência da superpopulação flutuante, latente e estagnada descritas por Marx (2017a) se materializam nestas novas formas de trabalho advindas da reestruturação produtiva que ampliam mais e mais a superexploração com retirada permanente dos sistemas contratuais de trabalho e de proteção social.

Na esfera da política o neo e o ultra neoliberalismo se apresentam no Estado máximo para o capital e mínimo para os trabalhadores, com ajustes fiscais, mercantilização das políticas públicas; contrarreformas do Estado, Administrativa, Previdenciária, Trabalhista, Sindical, do Ensino Superior, da Previdência Social; pela Privatização das Estatais e Serviços Públicos, com Ajustes Fiscais para o pagamento da dívida pública contraída pelos capitalistas para a manutenção deste modo de produção.

Acrescenta-se, ainda, a investida do capital na esfera da cultura com a chamada pósmodernidade, como sub-produto da ideologia neoliberal, com estímulo ao presentismo, atado à imediaticidade, ao aqui e agora, pela negação do passado e do futuro, na propagação do fim da história, no incentivo e disseminação do individualismo exacerbado, do irracionalismo, da moralização da "questão social", da naturalização da desigualdade, da militarização da vida cotidiana, da ampliação de normas de condutas coercitivas, punitivas, 
meritocráticas, na esfera do Estado e no mundo do trabalho, para controlar a classe trabalhadora.

Nessa orientação negam-se as análises macroestruturais, o legado marxiano e a tradição marxista, na prevalência das expressões fenomênicas e aparentes da realidade. Essa direção afeta sobremaneira a vida cotidiana, que traz elementos da imediaticidade e da heterogeneidade, plasmadas por imagens e representações e não por determinações articuladas entre objetividade e subjetividade. O conhecimento sensível se aparta do conhecimento racional, e portanto de sua dialeticidade processual, necessária ao ensino, à pesquisa, à produção de conhecimento e ao trabalho profissional como unidade indissociável entre teoria e prática. Interesses de classe, universais são substituídos por objetivos específicos, localistas, desconectados dos objetivos estruturantes e históricos. Autores antimarxistas e neomarxistas negam a centralidade do trabalho como prioridade ontológica e fundante do ser social que orienta as nossas diretrizes curriculares no projeto de formação e de nosso código de ética que norteia o nosso trabalho profissional. A ótica estabelecida se rege pela lógica de micro poderes pulverizados, dispersos, desvinculados das relações macro-societárias; presencia-se o forte combate aos partidos e sindicatos como instrumentos clássicos de lutas dos trabalhadores, como se estes já não se constituíssem mais em suas referências organizativas.

\section{OFENSIVA DO CAPITAL NA PARTICULARIDADE DO BRASIL}

Na América Latina a ofensiva do capital inicia-se em 1989, a partir do Consenso de Washington, elaborado pelo FMI-Fundo Monetário Internacional, Banco Mundial, Banco Interamericano de Desenvolvimento (BIRD) e pelo governo-norte americano na imposição da programática neoliberal para o continente; na lógica do desenvolvimento desigual e combinado em que os países periféricos, entre eles, os pertencentes aos continentes latino-americanos, africanos e asiáticos permanecem subordinados aos países capitalistas centrais sob o jugo imperialista na esfera internacional.

No Brasil, os anos 90 espelham portanto, a implantação do neoliberalismo sendo que na contracorrente, na direção de ruptura com o conservadorismo, construímos o Novo Código de Ética com seus fundamentos ontológicos (1993), a Nova Lei de Regulamentação da profissão (1993) e as Diretrizes Curriculares (1996) que dão materialidade ao nosso PEPP de continuidade à sua direção social conquistada, nos anos 80 , de reconhecimento dos profissionais como trabalhadores assalariados inscritos na divisão sócio-técnica, sexual e racial do trabalho e de nosso compromisso com a classe trabalhadora; bem como no fortalecimento dos cursos de graduação e de pós-graduação no país e consequentemente da pesquisa e do trabalho profissional, posto que pensar a intervenção pressupõe pensar a investigação, ambas voltadas para as necessidades humanas e sociais da maioria da população, a quem cotidianamente dirigimos nossa ação profissional e sob este prisma lutamos e continuamos lutando coletivamente em que as entidades organizativas da categoria e estudantil tem desempenhado um papel dirigente de combate, articulado às lutas e movimentos sociais classistas.

A programática neoliberal, inicia-se no final do Governo Sarney (89) implanta-se no Governo Collor de Melo (90/92); expande-se no governo Itamar Franco( 92/94), aprofundase e consolida-se nos dois governos de Fernando Henrique Cardoso-FHC (1995 a 2002) com:

Temporalis, Brasília (DF), ano 21, n. 41, p. 19-33, jan./jun. 2021. | ISSN 2238-1856 
a) as contrarreformas do estado, trabalhista, sindical, do ensino superior, (EaD², mestrados profissionalizantes, cursos sequenciais aligeirados); b) a implantação do Programa Comunidade Solidária com a prevalência do chamado $3^{\circ}$ setor na proliferação das Organizações Sociais- OS, Oscips- Organizações da Sociedade Civil de Interesse Público e ONGS- Organizações não governamentais.

Com o avanço da reestruturação produtiva e do neoliberalismo, o movimento sindical e popular se atém a lutas defensivas. A hegemonia social democrática e reformista se amplia; ocorre a filiação da Central Única dos Trabalhadores (CUT) à CIOLS, Central Internacional Social Democrata, e passa a atuar meramente no âmbito da institucionalidade, nas Câmaras Setoriais, com mesas de negociações compostas pelo patronato, pelo Estado e somente em 1/3 por trabalhadores, se distanciando da CUT classista, de lutas e ações diretas dos anos 80; em uma ação neocorporativista, voltada aos trabalhadores com contrato de trabalho nas empresas.

Importante destacar que as contrarreformas do ensino superior, nos dois governos de FHC, alteraram a natureza da universidade de Instituição Social para Organização Social (OS) subordinada aos interesses privados, tornando-os oligopólios mercantis do ensino, em uma concepção de universidade geracional na lógica operacional (CHAUÍ, 1999), alicerçada na racionalidade instrumental constitutiva do sucateamento e destruição do ensino público, com redução de recursos orçamentários, ampliação da privatização do ensino, e sua subordinação às demandas do mercado. As inovações propostas pela Lei de Diretrizes e Bases-LDB, se explicitam por meio de cursos sequenciais, exame nacional de curso, avaliações meramente quantitativas com ranqueamento, ensino à distância, e semipresencial na graduação, mestrados profissionalizantes com rebatimentos na formação, na pesquisa e no trabalho profissional.

Tais medidas tiveram continuidade nos dois governos de Lula da Silva (2003 a 2010) e em um governo e meio de Dilma Rousseff (2011 a 2016) sendo que os recursos para a educação no governo Lula significaram a irrisória quantia de 4,3\% do PIB semelhante ao percentual do governo $\mathrm{FHC}$, e a principal medida em relação às Instituições do Ensino Superior público e privado diz respeito, a compra pelo governo, de $20 \%$ a $25 \%$ das vagas ociosas das universidades privadas por meio do PROUNI (Programa Universidade para Todos), recurso que deveria destinar-se ao ensino público, laico, gratuito, universal, estatal, ampliando o acesso e permanência na universidade pública para os despossuídos e pauperizados do país, os filhos da classe trabalhadora, com a luta pelo fim do vestibular com acesso e política de permanência na universidade. $O$ decreto $n^{\circ} 6096$ regulamenta o programa de expansão do ensino superior nas universidades públicas, por meio da Reestruturação e Expansão das Universidade Federais (REUNI), de cursos de curta duração, de precarização do trabalho docente, em instalações precárias, ausência de instrumentos necessários para o funcionamento da formação universitária, com metas para ampliar numericamente as vagas conforme as exigências do Banco Mundial. O EaD é parte da estratégia de ampliação quantitativa de cursos aligeirados, que sob a égide da democratização do acesso, surge como única alternativa para milhares de jovens das camadas mais pauperizadas. $O$ aumento do EaD evolui para $4.500 \%$ e seu período de maior expansão se apresenta em 2008 (VIDAL, 2016). Essa lógica mercantil e privatista da educação, a qual combatemos

\footnotetext{
${ }^{2} \mathrm{As}(\mathrm{os})$ assistentes sociais formadas(os) pelo EaD já se constituem maioria.
}

Temporalis, Brasília (DF), ano 21, n. 41, p. 19-33, jan./jun. 2021. | ISSN 2238-1856 
servescoscocal Eutuas socaus temporalis

coletivamente por meio de nossas entidades constituem-se em ataques ao ensino, à pesquisa e ao trabalho profissional.

Os Anos de 2003 a 2016, foram administrados pelo PT, denominados governos democrático-populares, com oito anos de governo Lula, em seus dois mandatos, e um mandato e meio do governo de Dilma Rouseff, no período de seis anos, que tiveram apoio eleitoral das grandes massas de trabalhadores organizados, porém, seus governos deram continuidade à programática neoliberal. Os programas sociais voltados aos trabalhadores em extrema pobreza não foram acompanhados de políticas sociais estruturantes como as de emprego, o que fez com que o social desenvolvimentismo se caracterizasse como uma outra face do neoliberalismo em que as questões macroestruturais permaneceram na lógica do capital, com continuidade das contrarreformas Previdenciária e do Ensino Superior, desregulamentação das relações de trabalho e ajustes fiscais (ABRAMIDES, 2019).

A hegemonia do movimento social, a partir de 2003, adota a política de conciliação de classes entre trabalhadores e governo, atuando centralmente na institucionalidade, sem confrontar-se com o Partido dos Trabalhadores (PT), ao contrário, sendo correia de transmissão, cooptado por esse governo, que permaneceu com medidas liberalizantes à serviço do capital.

O quadro de perpetuação do neoliberalismo se aprofunda e ganha velocidade no governo golpista de Michel Temer, de 2016 a 2018, com a contrarreforma trabalhista, a lei da terceirização generalizada, ajustes fiscais, e a proposta de contra reforma previdenciária. O golpe de direita em 2016, parlamentar, midiático, com a presença de banqueiros, da Federação das Indústrias do Estado de São Paulo (FIESP), e do empresariado, com anuência do capital internacional estadunidense, se estabeleceu com o impeachment da presidente Dilma Rousseff do PT, sem crime de responsabilidade.

O governo Dilma havia sofrido uma grande queda de popularidade, em 2013, com o ajuste fiscal e medidas antipopulares de retração de direitos, seguindo os ditames do capital internacional, e frente a esse desgaste inicia-se a orquestração do golpe de direita desde 2015, para maior rapidez na implantação das medidas de ajustes neoliberais.

Naquele período ocorreram grandes e massivas mobilizações populares de rua, que se iniciaram com a luta dos estudantes secundaristas pelo passe-livre e a seguir foram ampliadas para os setores de trabalhadores empobrecidos das periferias, jovens sem trabalho, sem transporte, com precariedade habitacional, reivindicando serviços de saúde se insurgindo contra o governo do PT, pela precariedade de suas condições de vida e de trabalho, advinda de ajustes fiscais e pagamento da dívida pública. Neste período tem-se grande ocupações de escolas por secundaristas em oposição a projetos de educação nos estados com governos de direita, tentando emplacar a proposta da escola sem partido expressão do reacionarismo dominante.

Todavia, a esquerda presente nas massivas mobilizações e lutas sociais em 2013, era identificada, com o governo federal, pelas massas populares que ocupavam as ruas por todo o país, e neste processo, os movimentos de direita, Vem prá rua, e Movimento Brasil Livre (MBL), apoiados política e financeiramente pelos Institutos Liberais, entre eles o

Temporalis, Brasília (DF), ano 21, n. 41, p. 19-33, jan./jun. 2021. | ISSN 2238-1856 
Millennium no Brasil, iniciam e propagandeiam uma luta anti-sistêmica, moralizante, que vai criando bases de possibilidade eleitoral de um partido de direita para as eleições de 2018, porém o candidato do Partido Social Democrático Brasileiro (PSDB), Geraldo Alckmin, não consegue decolar, abrindo um caminho do anti-petismo de direita, com a avalanche da Lava-Jato orquestrada pela CIA norte americana, e a prisão política de Lula, por um ano e sete meses, para que não concorresse às eleições. Neste episódio também, embora com críticas aos governos do PT, nos posicionamos contra a prisão política de Lula, posto que efetivada sem qualquer prova nas acusações.

O governo golpista de Temer, no período de 2016 a 2018, estabelece seu programa de governo denominado ponte para o futuro que se confirmou como ponte para o abismo, instituindo a terceirização generalizada para atividades meio e fins, que ainda prevê a perda ou redução de direitos como a licença maternidade, a licença paternidade e o abono assiduidade, e impulsionou o encaminhamento de "[...] 55 projetos lesivos aos trabalhadores [...] (DEPARTAMENTO INTERSINDICAL DE ASSESSORIA PARLAMENTAR, 2016, não paginado), parte deles aprovados em seu governo. Entre esses projetos: a prevalência do negociado sobre o legislado, redução da jornada de trabalho com redução de salário, medidas de avanço da privatização e interferência em direitos sociais, de gênero, raça, etnia e orientação sexual, restrição na demarcação de terras indígenas, alteração do código penal sobre a questão do aborto, instituição do estatuto da família, retrocesso para grupos LGBTQIA+ e de mulheres, e instituição do estatuto do nascituro que ameaça o direito reprodutivo das mulheres entre outras medidas destrutivas; além da PEC da morte que alterou a constituição de 88 , ao instituir o teto dos gastos públicos congelando por 20 anos o orçamento das áreas sociais, como saúde, educação e assistência social para o pagamento da dívida pública contraída pela classe dominante e pela retirada do direito da população ao atendimento de serviços públicos essenciais (ABRAMIDES, 2019).

\section{O DESGOVERNO NEOFASCISTA DE JAIR BOLSONARO A PARTIR DE 2019}

No Brasil, desde o golpe de direita de 2016, exacerbado no desgoverno do capitão reformado protofascista de Jair Bolsonaro, expressa o reacionarismo de extrema direita em que a "Questão Social" volta a ser propagada como caso de polícia, remontando-se ao período histórico anterior aos anos 30, do século passado, com a proliferação ideopolítica atual de ídolos e mitos, de um simulacro, de negação dos valores humanitários e universais, na imantação do salve-se quem puder, em que a indústria cultural, os fake news, os cerceamentos e repressão às atividades políticas, públicas e coletivas à criminalização dos movimentos sociais traz em si a existência de uma vida moralizante e alienada, compatível com a negação da solidariedade. Se expandem cada vez mais a cultura do medo e do ódio, disseminando-se modos de vida pela autoajuda, pela fuga do mundo concreto e real, pela negação das determinações históricas e de classe.

O cenário da crise política e econômica do Brasil, que se aprofunda no governo de Bolsonaro, tem seu DNA na crise do capitalismo que eclodiu em 2008, nos EEUU, e se estendeu para a América Latina a partir de 2014. Desde 2016, com o golpe de direita e avanço das medidas demolidoras de direitos, os movimentos sociais ainda não conseguiram retomar com fôlego suas lutas o que se acentua a partir de 2019, com o 
servescoscocal Eutuas socaus temporalis

desgoverno instalado, em um contexto fortemente agravado pela pandemia a partir de 2020.

A decomposição do capitalismo nesse período demonstra que o capital financeiro descarta as vias democráticas e se movimenta à direita. A ascensão de Bolsonaro ocorre no acirramento da luta de classes por parte da burguesia e fragilidade da posição proletária; evidencia-se no governo corrupção, no âmbito pessoal, familiar, em seu grupo político miliciano, seguida por crises das frações inter-burguesas no planalto.

No âmbito da Educação, que atinge diretamente a formação profissional nas esferas da graduação e da pós-graduação em Serviço Social e em todas as áreas de conhecimento do Ensino Superior, o ex- Ministro Abraham Weintraub, do governo Bolsonaro, apresentou o Projeto Future-se que trata de ofensiva privatista com contingenciamento de $30 \%$ do custeio de capital dos Institutos Federais de Ensino Superior; ocasionando grandes dificuldades para pagar as despesas básicas de manutenção do ensino, acrescidas de ameaças à gratuidade do ensino público. Acrescentam-se os cortes orçamentários nas pesquisas, perseguição a projetos de ensino, com interferência nas eleições e intervenção nas universidades, com quebra de sua autonomia, apologia da ditadura e reverência aos torturadores, dilapidação do patrimônio público, incentivo ao ódio, à perpetuação do racismo, militarização do Estado, controle ideológico com o incentivo da escola sem partido, cerceamento da cultura e do direito de livre expressão, punição aos ativistas e movimentos sociais, aprovação da contra reforma previdenciária que coloca os aposentados em penúria absoluta, expressa um conjunto de iniquidades e barbarizarão da vida presentes na conjuntura atual em nosso país.

Em um ano de Ensino Remoto Emergencial (ERE) - temos nos posicionado por meio da ABEPSS, ANDES Sindicato Nacional, fortemente, uma vez mais contra o EaD, em defesa do ensino presencial de qualidade, e lutado contra as unidades de ensino e universidades, que se aproveitam do período de pandemia para instaurar ideias projetivas de ensino híbrido como uma modalidade de EaD. A precarização do trabalho tem se ampliado para docentes, em que o trabalho remoto expande-se barbaramente resultando em maior adoecimento no trabalho. Paralelamente a isso Acordos Coletivos não são assinados, reposições salariais são negadas. Em muitas universidades o ERE foi implantado de forma autoritária sem discussão com a comunidade universitária. A defesa da educação pública, laica, de qualidade, gratuita e universal permanece fortemente em nossas lutas acrescidas da luta contra a privatização e mercantilização do ensino.

Acrescenta-se, a negação da ciência em que o CNPQ retira bolsas para estudantes dos cursos de pós-graduação, o que bloqueia a formação e a pesquisa. De outro lado a CAPES sequestra bolsas de mestrandos e doutorandos que anteriormente retornavam aos programas da pós-graduação, reduzindo ainda mais a possibilidade dos estudantes cursarem mestrado e doutorado, ameaçando o fim de muitos programas que se mantém pelas bolsas que garantam os estudos e a pesquisa para os que pretendem dar continuidade à sua formação acadêmica de qualificação para a docência e consequentemente para o trabalho profissional.

As mobilizações e greve nacional da educação, ocorridas no Brasil, contra o corte dos recursos orçamentários e de combate à proliferação ideológica moralizante para a

Temporalis, Brasília (DF), ano 21, n. 41, p. 19-33, jan./jun. 2021. | ISSN 2238-1856 
educação; ocorridas em 15 e 30 de maio de 2019, assim como a Greve Geral de 14 de junho de 2019, contra a contrarreforma da educação, da previdência e demais ataques do governo Bolsonaro em relação à classe trabalhadora, foram extremamente importantes, as quais estivemos presentes e foram apoiadas pelas nossas entidades organizativas em articulação com as lutas da educação por meio do ANDES Sindicato Nacional, associações de docentes nas universidades, juntamente com os movimentos sociais, sindicais e populares. Sem dúvida se constituíram em referência de lutas sociais, porém ainda insuficientes, posto que a classe trabalhadora, não tem conseguido responder com suas forças autônomas e independentes por meio de uma Greve Geral de mais largo alcance, de forma unificada.

Sem dúvida, há setores classistas no movimento sindical que organizam-se na Conlutas e Intersindical, bem como os docentes, no ANDES-Sindicato Nacional, porém o grande contingente proletário, de sindicatos operários encontram-se filiados à CUT, e é preciso continuar disputando seus sindicatos para um campo classista, retomar as oposições sindicais, investir em trabalho de base, nas fábricas, nos bairros, nas escolas, nas periferias, impulsionar a socialização de informações aos setores populares, mais pauperizados, com os quais trabalhamos cotidianamente, na ação profissional, que os apoie em suas reivindicações e combates. Os movimentos sociais embora na defensiva mediante os sucessivos ataques tem se movido em suas lutas cotidianas na defesa da vida e dos direitos, no campo e na cidade estabelecendo formas coletivas de práxis.

É um desafio de centralidade para os movimentos sociais específicos e gerais da cidade e do campo, que possam vincular as lutas imediatas em defesa do salário e do emprego, da educação e saúde públicas, da reforma agrária e urbana, da demarcação de terras indígenas, da política de seguridade social e contra as contrarreformas do Estado, administrativa, do ensino superior, previdenciária, sindical, trabalhista, contra a terceirização e o trabalho intermitente; contra a EC- Emenda Constitucional 95, contra o racismo estrutural e institucional, a LGBTQIA+fobia, o patriarcado, o machismo, o negacionismo, articulando essas lutas, fortalecendo os comitês populares, as organizações por local de trabalho, nas fábricas, nas escolas, nas universidades e nos bairros. O momento exige jogar nossas forças na luta concreta, com mobilizações de massa unificadas e com greves para por Abaixo o (des)Bolsonaro-Mourão articulado à luta anticapitalista.

\section{A CONJUNTURA DO PAÍS EM MEIO À CRISE SANITÁRIA NO INTERIOR DA CRISE DO CAPITAL: PARTICULARIDADE DO BRASIL SOB O (DES) GOVERNO BOLSONARO}

Quero primeiramente prestar minha solidariedade e meus sentimentos às famílias das 292.856 pessoas que morreram pela COVID 19, confirmadas até às 18:00 h deste domingo 21/03/2021, momento que estou concluindo este artigo. Situação que figura o Brasil como o segundo país com maior número de óbitos do planeta, e o primeiro com maior número de óbitos diários, em torno de 2.880 , entre esses muitos profissionais da saúde, que estão em linha de frente, aí incluídos muitas(os) assistentes sociais. Essas mortes, que se ampliam assustadoramente, ocorrem sob o desgoverno de um presidente protofascista, negacionista, genocida, ultra neoliberal, miliciano, reacionário, de extrema direita que vem destruindo, em plena pandemia, as conquistas históricas dos trabalhadores fruto de muita luta no patamar de autonomia e independência de classe com medidas provisórias, PECs e contrarreformas em curso acrescidas das privatizações. 
A crise sanitária escancarou a crise estrutural do capital; no Brasil, o isolamento social é decretado em 16/03/2020, sendo que notícias indicam que já haviam infectados desde o carnaval. O (des) governo Bolsonaro trouxe para o planalto sua estratégia de campanha de traços neofascistas de um governo privatista e entreguista ao grande capital internacional estadunidense, que teve em Trump, ex-presidente dos EEUU, também de ultradireita, sua grande referência; ambos dão às costas para a Organização Mundial da Saúde (OMS) em relação às orientações necessárias para o enfrentamento da pandemia da COVID-19. O desgoverno se colocou na pandemia de forma negacionista desde o primeiro momento ao dizer que se tratava de uma gripezinha, se contrapôs ao isolamento social; se posiciona contra a saúde pública por meio de gestos e discursos; comete um genocídio ao ignorar a situação de falta de oxigênio no Amazonas; incentiva aglomerações com carreatas e manifestações e ainda possui um núcleo duro de fieis seguidores em torno de $25 \%$, embora tenha diminuído em relação a momentos anteriores à pandemia; um desgoverno irracionalista; miliciano; além de misógino, racista, de ódio aos pobres e militantes de esquerda; anti-direitos democráticos, anti-ciência; seus ministros e assessores são formados em grande parte por militares; e sua base de sustentação no Congresso Nacional é composta por fundamentalistas de extrema direita.

Bolsonaro chegou a propor ao STF- Supremo Tribunal Federal, uma ação contra medidas de proteção da doença adotada pelos governadores. No dia 05/02/2021, às custas de trilhões de reais retirados do fundo público, como moeda de troca aos parlamentares, consegue de forma espúria eleger os líderes do Senado e da Câmara. O ministro da economia Paulo Guedes em sua Economia de Guerra deslocou 1, trilhão e 216 bilhões de reais para os bancos, 200 bilhões para as grandes empresas e somente 82,2 bilhões para combater a epidemia na esfera federal.

O SUS, Sistema de Saúde pública, universal, gratuito, conquista da classe trabalhadora em luta nos anos 80, da qual nós assistentes sociais participamos ativamente e continuamos em sua defesa, contra sua privatização, tem dado um suporte nesta pandemia, porém não de forma suficiente, posto que o SUS já se encontrava muito debilitado pela retirada de recursos para as áreas sociais advinda da PEC 95 do governo Temer.

Enquanto o governo federal repassa trilhões para bancos e grandes empresas privadas, retira dos trabalhadores seus parcos recursos por meio de MP 936 que libera às empresas reduzir em até $70 \%$ o valor dos salários e em até $25 \%$ o salário para quem ganha até 3.135,00 reais, o que coloca os trabalhadores de baixa renda ainda em maior penúria. A PEC 32/2020 avança para ser aprovada e prevê o congelamento dos reajustes dos trabalhadores em serviço público nas esferas, municipal, estadual e federal bem como estanca a promoção na carreira e impede a realização de concursos públicos, com a proposta de contratos terceirizados irrestritos para todas as áreas. De um orçamento de 130 bilhões relativos à esfera federal é destinado o valor de 60 bilhões, aos municípios e estados, e destes somente 10 bilhões são revertidos para a saúde e assistência social, sendo que a outra parte, 70 bilhões, é atribuída ao pagamento da dívida pública; que não foi contraída pelos trabalhadores, mas pelas empresas privadas dos grandes oligopólios. Agrega-se a esse escândalo a compra pelo Banco Central de títulos podres advindos dos bancos privados que não serão vendidos; ou seja é a transferência do fundo público para as oligarquias privadas o que ocasiona mais dívida pública e menos políticas e serviços públicos que deveriam estar voltados para a esmagadora maioria da população.

Temporalis, Brasília (DF), ano 21, n. 41, p. 19-33, jan./jun. 2021. | ISSN 2238-1856 
O auxílio emergencial na pandemia de parcos $\$ 600,00$ reais ao mês (Bolsonaro propôs $\mathrm{R} \$ 200,00)$, foram irrisórios para uma população desempregada, em trabalho informal e com salários reduzidos, sendo que em dezembro de 2020 este auxílio foi interrompido. $O$ auxílio emergencial para 2021 deve se iniciar em abril, regulamentado pela MP 1039 que será pago em quatro parcelas para 45,6 milhões de pessoas, ao invés dos 68 milhões que receberam em 2020 (AUMENTO..., 2021). De outro lado, os valores oscilarão entre $\mathrm{R} \$ 150,00, \mathrm{R} \$ 250,00$ e $\mathrm{R} \$ 375,00$ mensais. Nossa luta imediata é para que todos retornem a receber e no mínimo a quantia anterior, que já era pequena, posto que sem esta medida serão milhões a morrer de fome e de acordo com pesquisa recém- divulgada $68 \%$ da população residente nas favelas não tem como comprar alimento. No início da pandemia eram 13 milhões de desempregados, somados aos que foram demitidos na pandemia e os desalentados, que não estão procurando emprego, esta cifra chega a 20 milhões de pessoas, acrescidos de 38 milhões de trabalhadores informais, que com a lei da terceirização e trabalho intermitente já aprovados, a previsão é de que a maioria dos trabalhadores estará sem nenhum sistema de proteção trabalhista em 2024.

Cabe registrar que o maior número de mortos pela COVID-19, encontra-se entre a população mais empobrecida, em sua maioria negros(as)- pretos(as) e pardos(as)- que, historicamente, sofrem do racismo estrutural, desde o período de colonização na formação sócio-histórica do Brasil, quando seus corpos foram sequestrados de África e escravizados, servindo à assim chamada acumulação primitiva capitalista no país. Bem como as populações indígenas, quilombolas, ribeirinhas, originárias, atingidas por barragem que vem sendo cada vez mais dizimadas e oprimidas, expulsas de suas terras e assassinadas pelo agronegócio, grileiros e mineradoras.

Milhares de trabalhadores e trabalhadoras moradores de morros e favelas nas periferias das cidades e que vivem em situação de rua, que em sua grande maioria estão desempregados, em trabalhos informais, precários, temporários, intermitentes, são os mais pauperizados, e que ampliam a superpopulação relativa em sua condição latente, flutuante e estagnada, sem direitos sociais e trabalhistas. Os mais exploradas(os) da classe trabalhadora e oprimidos(as) em sua condição de classe, gênero, raça, etnia, orientação sexual, por residirem em áreas super populosas, precárias sem saneamento básico, condições de habitabilidade e qualquer sistema de proteção social, além de utilizarem transportes públicos lotados para se locomoveram para tentar alguma forma de subsistência. Estes trabalhadores tem se organizado nas comunidades, nos bairros, nas associações de moradores, com apoio à alimentação, máscaras protetoras, álcool em gel, em verdadeiras brigadas de cooperativas nos setores populares. Trabalhadores, inseridos ou não no mercado de trabalho estão em luta, são demandatários dos serviços sociais com os quais trabalhamos nos múltiplos espaços sócio-ocupacionais e devemos prestar solidariedade ativa a estes que vem resistindo em movimentos sociais, coletivos, saraus, ocupações de terra, mobilizações e greves parciais.

Importante salientar que, em 2020, ocorreram greves nos correios, dos petroleiros, dos operários da Volks, e de entregadores por aplicativos, mediante a precarização das condições de trabalho, falta de segurança e baixos salários. A Ford indústria automobilística que estava no país há 100 anos desativa suas fábricas no Brasil, em janeiro de 2021, o que significa mais de 5.000 operários desempregados. Nos últimos quatro anos 36 fábricas foram fechadas com mais de 100 mil trabalhadores demitidos de seus postos

Temporalis, Brasília (DF), ano 21, n. 41, p. 19-33, jan./jun. 2021. | ISSN 2238-1856 


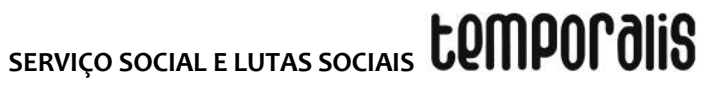

de trabalho. A CUT, CTB- Central de Trabalhadores Trabalhadoras do Brasil e Força Sindical estabeleceram negociações de acordos com o patronato quando as bandeiras de luta deveriam ser definidas em assembleias massivas, para ocupação de fábricas, controle operário, constituição dos comitês de base, estatização das fábricas sem indenização, organização do movimento local em defesa dos empregos. Esse é o ponto de partida para defesa da economia nacional e das condições de existência da maioria oprimida.

\section{CONSIDERAÇÕES FINAIS}

As notas conclusivas apontam os desafios para as lutas imediatas dos movimentos sociais, das (os) assistentes sociais e do conjunto dos trabalhadores na direção de uma nova sociabilidade: a- Lutar para por abaixo o governo Bolsonaro/ Mourão; b- dar continuidade à luta classista, unitária dos trabalhador@s contra esse conjunto de Contrarreformas ( Trabalhista, Administrativa, Previdenciária, da Educação Superior e pelo fim da terceirização e trabalho intermitente) aí incluídas as MPS reacionárias e de Economia de Guerra; o fim da EC 95 que congela o orçamento das áreas sociais, com a elevação dos gastos em saúde, seguridade, assistência social e educação; c-Retomada da organização sindical e popular com trabalho de base desde os locais de trabalho, bairros, fábricas, escolas, universidades; d-Lutar contra o desemprego e todas as formas de precarização e destruição das relações de trabalho; e-Retomar as ações diretas com mobilizações e greves; f-Lutar contra as privatizações do serviço público e das estatais; g-Renda básica a todas as famílias sem renda; h- Recursos imediatos para a saúde, na defesa do SUS sob controle dos trabalhadores; i-Vacinação pública para toda população; j-Taxação das grandes fortunas; k- Manutenção dos empregos e dos salários; I-Nenhuma demissão de trabalhadores e Interrupção imediata do trabalho nas empresas aos mais de 60 anos e de todos em situação de risco; m-Preservação da vida em atividades que não possam ser interrompidas; n-Deslocamento seguro ao ambiente de trabalho; o-Não pagamento da dívida interna e externa que não foi contraída pelos trabalhadores; p-Controle popular e fiscalização dos preços de medicamentos, combustíveis e alimentos; q-Comitês populares de bairro em defesa sanitária, emprego e salário; r-Soberania popular.

A conjuntura do país exige que continuemos na luta. O que a vida quer da gente é coragem, como nos diz com maestria o escritor, diplomata, novelista, contista e médico João Guimarães Rosa.. Ousadia, radicalidade, aprofundamento teórico, compromisso com a socialização das informações e dos direitos. Precisamos recuperar experiências de trabalho de base, de educação popular, incentivar e apoiar os coletivos de solidariedade na periferia junto às camadas mais empobrecidas da população. Lutar incessantemente como temos lutado contra as opressões de classe, gênero, raça, etnia, orientação sexual e geracional, assim como colocar nossas pesquisas, nosso trabalho à serviço da classe trabalhadora.

A decomposição do capitalismo expressa sua decadência, momento em que as forças produtivas entraram em antagonismo com as relações sociais de produção, mas ao mesmo tempo o capital impõe sua hegemonia internacional e força de exploração e dominação de classe. As condições objetivas para um processo de revolução social estão postas: fome, miséria, desemprego estrutural que se alastra, destruição de direitos sociais e trabalhistas, queima de excedente econômico, exacerbação da desigualdade, avassaladora guerra contra os povos, destruição de forças produtivas e da natureza, extermínio das populações pobres, exploradas e oprimidas; genocídio da população negra e jovem das periferias e

Temporalis, Brasília (DF), ano 21, n. 41, p. 19-33, jan./jun. 2021. | ISSN 2238-1856 
morros das grandes cidades, assassinato da população indígena e ribeirinha pelas mineradoras e agro-negócio. Porém, as condições subjetivas estão por ser criadas, apesar das mobilizações sociais sociais e luta dos trabalhadores, onde estamos inseridas(os) como parte da classe trabalhadora e como profissionais, atuando nas camadas populares mais empobrecidas, as lutas ainda são insuficientes. Os ataques do capital e do desgoverno neofascista são brutais, há um descrédito das massas não organizadas com a política, o freio social democrático da política de conciliação de classes ainda permanece hegemônico e não há programas e partidos revolucionários, para um processo histórico anticapitalista e socialista, comum a todas e todos na direção de uma sociedade emancipada. As condições para se enfrentar a barbárie precisam ser criadas, no patamar de autonomia e independência de classe com um programa da classe.

A realidade sócio-histórica, conjuntural e estrutural nos coloca desafios como apresentamos, a serem enfrentados na formação profissional, no âmbito da graduação e da pós graduação e no exercício profissional, o que requer análise concreta desses demandas, articulação às lutas sociais, entre os sujeitos sociais coletivos envolvidos como professores, estudantes, pesquisadores, assistentes sociais, servidores públicos, usuários dos serviços, supervisoras de campo, movimentos sociais, sindicais e populares, no âmbito da classe trabalhadora no sentido da denúncia, da articulação de projetos de resistência, de contestação, de rebeldia quanto a esses estado de coisas de destruição das condições de vida e trabalho. Portanto, a luta contra qualquer tipo de opressão, preconceito e ou discriminação articula-se à luta contra a exploração, posto que sem sua superação, não há possibilidade de superação da ordem do capital e construção do projeto de emancipação humana.

\section{REFERÊNCIAS}

ABRAMIDES, Maria Beatriz Costa. O Projeto Ético-Político do Serviço Social Brasileiro: ruptura com o conservadorismo. São Paulo: Cortez Editora, 2019.

AUMENTO emergencial 2021. São Paulo, Valor Investe, 2021. Disponível em: http://valorinveste.globo.com. Acesso em: 20 mar. 2021. https://valorinveste.globo.com/busca?q=aux\%C3\%ADlio+emergencial+2021\&page=1

CHAUÍ, Marilena. A Universidade operacional: atual reforma do Estado ameaça esvaziar a instituição universitária com sua lógica de mercado. Folha de São Paulo, São Paulo, 9 maio 1999.

DEPARTAMENTO INTERSINDICAL DE ASSESSORIA PARLAMENTAR (DIAP). DIAP aponta 55 projetos contra os trabalhadores. Brasília (DF), CUT, 10 mar. 2016. Disponível em: https://www.cut.org.br/noticias/diap-aponta-55-ameacas-aos-direitos-dos-trabalhadoresa5a6.

LENIN,V.I. Imperialismo: Estágio Superior do Capitalismo. Editora Expressão Popular: São Paulo, 2012.

MARX, Karl. O Capital Livro I-Crítica da Economia Política. O processo de Produção do Capital. Capítulo 23. A lei Geral da Acumulação Capitalista - 4. Diferentes Formas de

Temporalis, Brasília (DF), ano 21, n. 41, p. 19-33, jan./jun. 2021. | ISSN 2238-1856 
serves soccal E Lutas socaus temporalis

existência da superpopulação relativa. In: O capital. Livro I, Vol. 1. São Paulo: Boitempo Editorial, 2017a.

MARX, Karl. Capítulo 24- A assim chamada Acumulação Primitiva. In: O capital. Livro I, Vol. 1. São Paulo: Boitempo Editorial, 2017b.

VIDAL, Karina C. O ensino à distância: um reflexo da expansão mercantilizada da educação superior e os impactos no Serviço Social. 2016. Dissertação ( Mestrado em Serviço Social)- Programa de Estudos Pós-Graduados em Serviço Social da Faculdade de Ciências Sociais da Pontifícia Universidade Católica de São Paulo, São Paulo, 2016.

\section{BIBLIOGRAFIA COMPLEMENTAR CONSULTADA}

ASSOCIAÇÃO BRASILEIRA DE ENSINO E PESQUISA EM SERVIÇO SOCIAL. ABEPSS faz balanço de posicionamentos e ações em defesa do Serviço social na pandemia. Notícias, Brasília (DF), 19 mar. 2021. Disponível em: http://www.abepss.org.br/noticias/wwwabepssorgbrbalancopandemia-435. Acesso em: 8 ago. 2021.

CONSELHO FEDERAL DE SERVIÇO SOCIAL (CFESS). Teletrabalho e Teleperícia: orientações para assistentes sociais. Disponível em: http://www.cfess.org.br/arquivos/Nota-teletrabalho-telepericiacfess.pdf. Brasília (DF), [2020]. Acesso em: 18 nov. 2020.

MAIOR, Jorge Luís Souto. Colunas. Disponível em: https://blogdaboitempo.com.br/category/colunas/jorge-luiz-souto-maior-colunas/. Acesso em: 15 out. 2020.

NETTO, J. P. Uma face contemporânea da barbárie. In: ENCONTRO INTERNACIONAL “CIVILIZAÇÃO OU BARBÁRIE” SERPA,3., Marília, 2010. Anais [...]. Marília: Unesp, 30-31out. 1nov. 2010. Disponível em:

http://www2.marilia.unesp.br/revistas/index.php/novosrumos/article/view/3436/2657. Acesso em: 1 nov. 2010.

POR MASSAS; Corrente Proletária da Educação, ano 7, 15 fev. 2021. Disponível em: http://pormassas.org/wp-content/uploads/2021/02/Declaracao-POR-Ford-15-de-fevereirode-2020.pdf. Acesso em: 19 mar. 2021.

\section{Maria Beatriz Costa Abramides}

Graduação em Serviço Social pela Pontifícia Universidade Católica de São Paulo-PUC-SP (1971), mestrado em Serviço Social pela PUCSP (1992), doutorado em Serviço Social PUCSP(2006), pós-doutorado pelo Instituto de História Contemporânea-IHC da Universidade Nova de Lisboa-UNL-Portugal (2019). Professora do Curso de Graduação em Serviço Social da PUCSP (1980 / 2012) e do Programa de Estudos Pós-Graduados em Serviço Social da PUCSP desde 2012. 